\title{
Contributions to the smut fungi of Africa. 3. First record of Microbotryum polygoni-alati
}

\section{Teodor T. Denchev* \& Cvetomir M. Denchev}

Institute of Biodiversity and Ecosystem Research, Bulgarian Academy of Sciences, 2 Gagarin St., 1113 Sofia, Bulgaria

Received 11 December 2017 / Accepted 21 December 2017 / Published 31 December 2017

Denchev, T.T. \& Denchev, C.M. 2017. Contributions to the smut fungi of Africa. 3. First record of Microbotryum polygoni-alati. - Mycobiota 7: 19-24. doi: 10.12664/mycobiota.2017.07.04

Abstract. Microbotryum polygoni-alati, known only from India and China, is reported for the first time from Africa (from Ethiopia).

Key words: Africa, Ethiopia, Microbotryaceae, Microbotryum polygoni-alati, Persicaria nepalensis, Polygonaceae, smut fungi, taxonomy

\section{Introduction}

In the third article from our series devoted to accumulation of new data on the smut fungi of Africa (see Denchev \& Denchev 2016, 2017), Microbotryum polygoni-alati is reported for the first time from Africa.

\section{Material and methods}

Specimens from the fungal dried reference collection of University of Copenhagen (C) were examined with a light microscope (LM) and scanning electron microscope (SEM). For LM observations and measurements, spores were mounted in lactoglycerol solution (w : la : $\mathrm{gl}=1: 1: 2$ ) on glass slides, gently heated to boiling point to rehydrate the spores, and then cooled. The measurements of spores are given in the form: min-max (extreme values) (mean \pm 1 standard deviation). For SEM, spores were attached to specimen holders by double-sided adhesive tape and coated with gold in an ion sputter. The surface structure of spores was observed and photographed at $10 \mathrm{kV}$ accelerating voltage using a Hitachi SU3500 scanning electron microscope. The description given below is based entirely on the specimens examined.

\footnotetext{
*Corresponding author: e-mail: ttdenchev@gmail.com
} 


\section{Taxonomy}

Microbotryum polygoni-alati (Thirum. \& Pavgi) Vánky, Mycotaxon 67: 49, 1998.

三Ustilago polygoni-alati Thirum. \& Pavgi, Sydowia 20: 24, 1968['1966'].

Sori in the inflorescence (destroying single or groups of flowers, forming irregular bodies, Fig. 2), in some leaves (forming irregular bodies), and/or on the stem (forming irregular or reniform bodies, Fig. 3); 2-10 mm long, covered by a yellow-brown peridium that ruptures irregularly, exposing semi-agglutinated to powdery, dark purple spore mass. Spores subglobose, globose or broadly ellipsoidal, (9.5-)10-13(-14.5) $\times(9.0-) 9.5-12.5(-13)$ $(11.7 \pm 0.8 \times 11.0 \pm 0.7) \mu \mathrm{m}(\mathrm{n}=100)$, medium purplish brown; spore wall $1.0-1.4 \mu \mathrm{m}$ thick, lowly reticulate to minutely verruculose (as seen by LM), spore profile not affected or very slightly affected (Figs 4, 5). In SEM spore wall reticulate, often incompletely reticulate, muri low, $0.2-0.3 \mu \mathrm{m}$ high, often with warts, mainly in the common points of the meshes; the interspaces often perforate with up to 3(-5) holes per interspace, sometimes with $1(-2)$ warts (Figs 6, 7). Immature spores abundant, intermixed with mature ones, hyaline to light purplish brown, smaller than the mature spores (Fig. 4).

Specimen examined - On Persicaria nepalensis (Meisn.) H. Gross (det. K. Vollesen, as Polygonum nepalense): ETHIOPIA, OROMIA REGION, ILLUBABOR ZONE (former Illubabor Prov.), $34 \mathrm{~km} \mathrm{~S}$ of Gore, $6 \mathrm{~km} \mathrm{~S}$ of Gurbadima, along Gore-Moccha track, $8^{\circ} 00^{\prime}$ N, 35²7' E, 1750 m, Aningeria-forest, 17 Dec 1972, leg. I. Friis et al., Danish-Ethiopian Botanical Expedition 1972-1973, no. 1810 (C).

Distribution — On Polygonaceae: Persicaria nepalensis (syn. Polygonum nepalense Meisn., P. alatum Buch.-Ham. ex D. Don); East Africa (Ethiopia) (Fig. 1) and Asia (India, China - Sichuan, Yunnan).

This species is tentatively treated as belonging to the genus Microbotryum.

The spores of $M$. polygoni-alati possess characteristic ornamentation - a low reticulum (formed by low muri, often with warts, mainly in the common points of the meshes), and interspaces which are often perforate with up to $3(-5)$ holes, sometimes, with $1(-2)$ warts.

Microbotryum polygoni-alati was known only from India (Thirumalachar \& Pavgi 1968; Vánky 2007) and China - Sichuan (Guo 1993) and Yunnan (Kakishima et al. 2000). It is reported here for the first time from Africa.

Microbotryum nepalense (Liro) Vánky, Mycotaxon 67: 47, 1998.

Figs 8-11

$\equiv$ Ustilago nepalensis Liro, Annales Academiae Scientiarum Fennicae, Ser. A, 17(1): 184, 1924.

For its descriptions and illustrations see Kakishima et al. (2000) and Vánky (2005, 2011).

Specimen examined - On Persicaria nepalensis (Meisn.) H. Gross (det. I. Friis, as Polygonum nepalense): ETHIOPIA, OROMIA REGION, JIMMA ZONE (former Kaffa Prov.), $1.5 \mathrm{~km} \mathrm{NW}$ of Aro, at the road between Jimma and Agaro, $7^{\circ} 49^{\prime} \mathrm{N}, 36^{\circ} 45^{\prime} \mathrm{E}$, 1700-1800 m, Coffe-plantation, 7 Nov 1970, leg. I. Friis, A. Hounde \& K. Jacobsen, Danish Botanical Expedition to Ethiopia 1970, no. 144 (C).

Distribution - On Polygonaceae: Persicaria nepalensis; East Africa (Ethiopia) (Fig. 1) and Asia. 

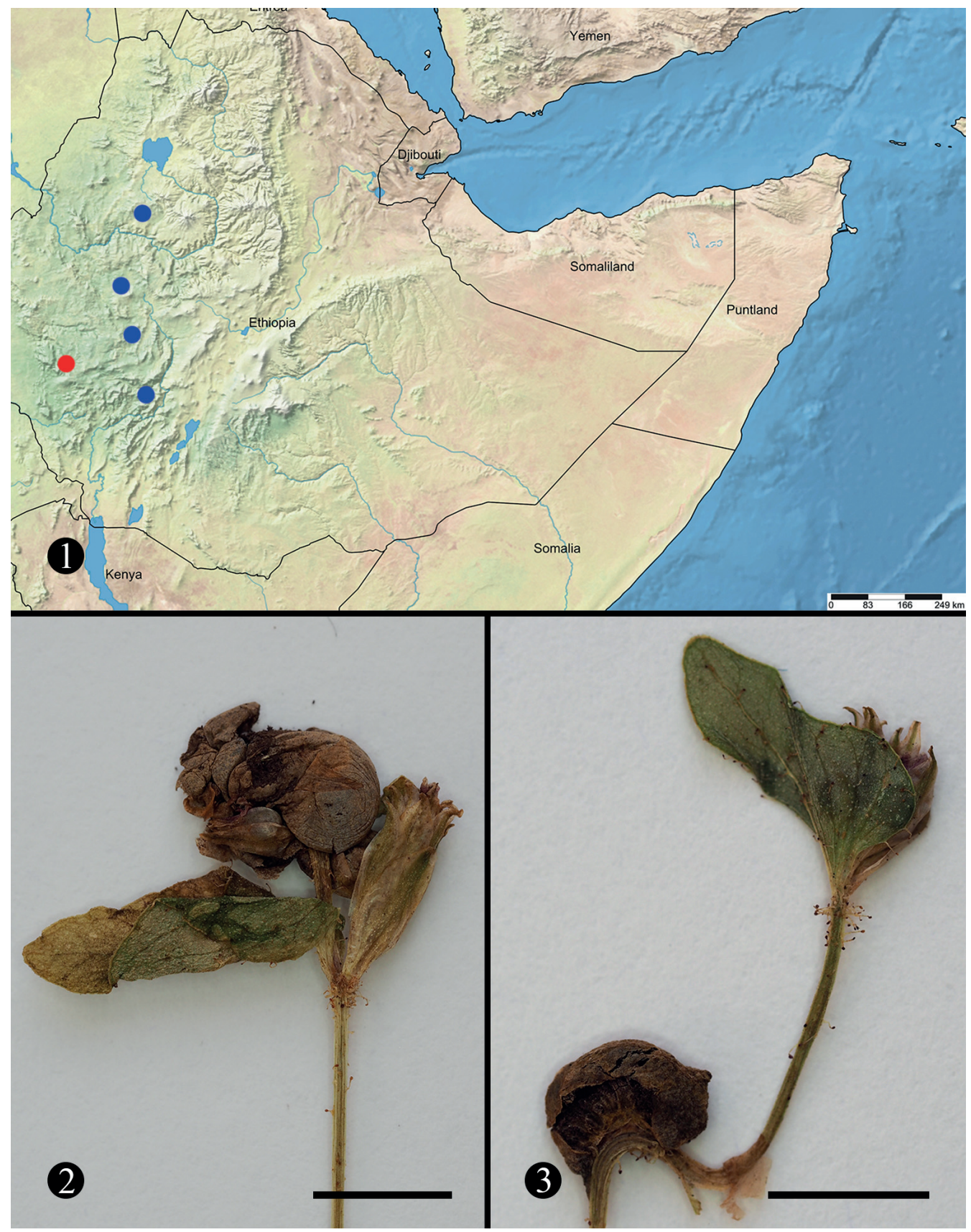

Fig. 1. Geographic distribution of Microbotryum polygoni-alati (red circle) and M. nepalense (blue circles) in Africa (generated with SimpleMappr, Shorthouse 2010). Figs 2, 3. Microbotryum polygoni-alati on Persicaria nepalensis from Ethiopia (I. Friis et al., coll. no. 1810, C) - habit. 2. Sorus in the inflorescence, scale bar $=5 \mathrm{~mm}$. 3. Sorus on the stem, scale bar $=5 \mathrm{~mm}$ 


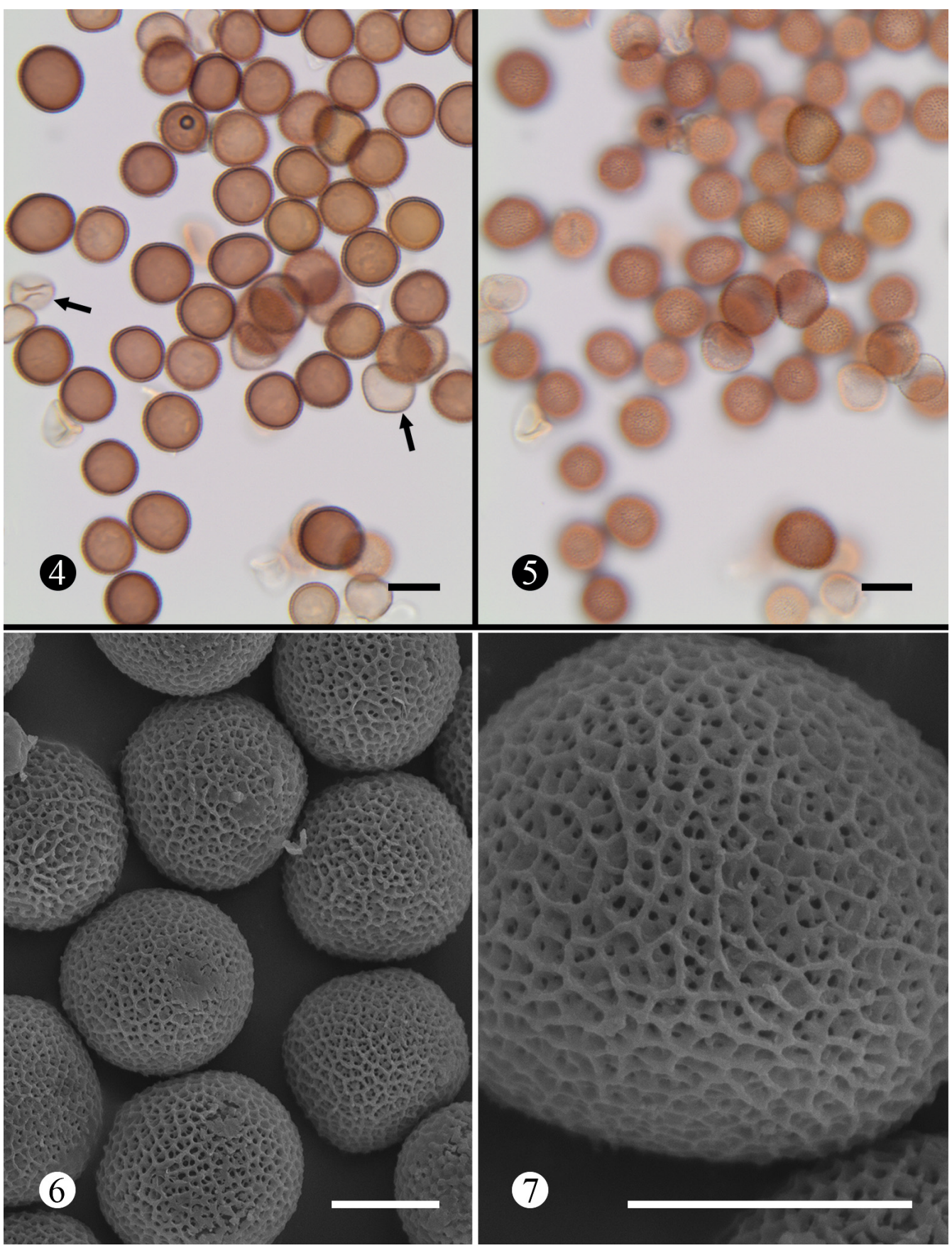

Figs 4-7. Microbotryum polygoni-alati on Persicaria nepalensis from Ethiopia (I. Friis et al., coll. no. 1810, C). 4, 5. Spores in LM (in median and surface view, respectively), scale bars $=10 \mu \mathrm{m} .6,7$. Spores in SEM, scale bars $=5 \mu \mathrm{m}$. In Fig. 4, black arrows indicate immature spores. 


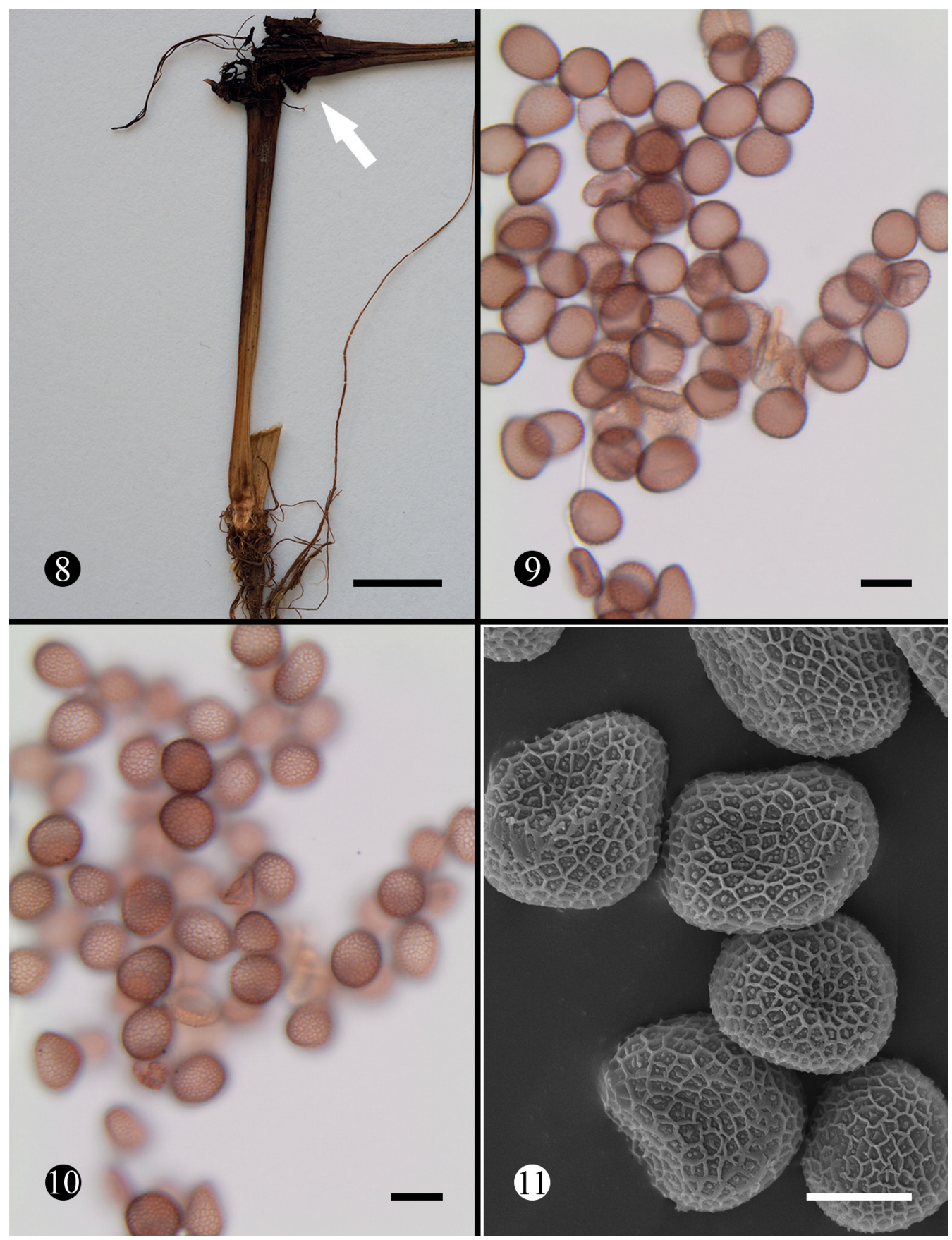

Figs 8-11. Microbotryum nepalense on Persicaria nepalensis from Ethiopia (I. Friis et al., coll. no. 144, C). 8. Habit, scale bar $=1 \mathrm{~cm} .9,10$. Spores in LM (in median and surface view, respectively), scale bars $=10 \mu \mathrm{m}$. 11. Spores in SEM, scale bar $=5 \mu \mathrm{m}$. In Fig. 8, white arrow shows the sorus. 
This species is tentatively treated as belonging to the genus Microbotryum.

From Africa, $M$. nepalense is known only from Ethiopia (from Amhara Region and Oromia Region - Vánky 2005; Vánky et al. 2011). The specimen, recorded herein, is collected from a new locality in Oromia Region. Usually, the sori of $M$. nepalense are formed closely below the inflorescence, while in the examined specimen, the sorus is developed in the lowest part of the stem (Fig. 8).

Acknowledgements. This research received support (Grants nos. DK-TAF-5927, FRTAF-6628) from the SYNTHESYS Project http://www.synthesys.info/ which is financed by European Community Research Infrastructure Action under the FP7 "Capacities” Program. The assistance of Mrs Geraldine Toutirais (National Museum of Natural History, Paris) is kindly acknowledged.

\section{References}

Denchev, T.T. \& Denchev, C.M. 2016. Contribution to the smut fungi of Africa. 1. - Mycobiota 6: 21-27. https://dx.doi.org/10.12664/mycobiota.2016.06.02

Denchev, T.T. \& Denchev, C.M. 2017. Contribution to the smut fungi of Africa. 2. A second locality of Anthracocystis compacta. - Mycobiota 7: 13-18. https://dx.doi.org/10.12664/mycobiota.2017.07.03

Guo, L. 1993. Ustilago deyeuxiae sp. nov. and three smut species new to China. - Mycosystema 6: 51-55.

Kakishima, M., Denchev, C.M., Zhou, X. \& Zang, M. 2000. Smut fungi from Yunnan Province, China, collected in 1998. - Bulletin of the National Science Museum, Tokyo, Series B (Botany) 26(1): 23-34.

Shorthouse, D.P. 2010. SimpleMappr, an online tool to produce publication-quality point maps. Available from: http://www.simplemappr.net (accessed 9 December 2017).

Thirumalachar, M.J. \& Pavgi, M.S. 1968['1966']. Notes on some Indian Ustilagineae. IX. - Sydowia 20: $21-27+$ Pls I-II.

Vánky, K. 2005. The smut fungi of Ethiopia and Erithrea. - Lidia 6: 93-120.

Vánky, K. 2007. Smut fungi of the Indian Subcontinent. - Polish Botanical Studies 26: 1-265.

Vánky, K. 2011['2012']. Smut fungi of the world. APS Press, St. Paul, Minnesota, USA.

Vánky, K., Vánky, C. \& Denchev, C.M. 2011. Smut fungi in Africa - a checklist. - Mycologia Balcanica 8: $1-77$. 